Research Article

\title{
Research on the Incentive Mechanism of the Pension Service Supply Chain under Asymmetric Information
}

\author{
Xiaohua Chen \\ School of Economic and Management, Harbin University of Science and Technology, Harbin 15008, China \\ Correspondence should be addressed to Xiaohua Chen; zcxh@hrbust.edu.cn
}

Received 25 May 2020; Revised 23 February 2021; Accepted 28 July 2021; Published 4 August 2021

Academic Editor: Isabella Torcicollo

Copyright (c) 2021 Xiaohua Chen. This is an open access article distributed under the Creative Commons Attribution License, which permits unrestricted use, distribution, and reproduction in any medium, provided the original work is properly cited.

\begin{abstract}
The information asymmetry between the pension service integrator and the pension service providers will affect the efficiency of the whole supply chain, and information sharing can solve this problem to a certain extent. To achieve information sharing, mutual trust is the first condition and mutual trust is also one of the important means of endogenous incentives. In this paper, the trust incentive coefficient is embedded in the principal-agent model. Considering the service capability coefficient, the communication degree coefficient, and the information sharing degree coefficient of the pension service providers, the trust incentive model of the supply chain of the pension service is constructed, the model is solved, and the conclusion is drawn. Finally, the correctness of the conclusion is verified by the numerical simulation using SAS software. The final results show that, under the condition of information asymmetry, the trust incentive coefficient of the pension service integrator to the pension service providers is positively correlated with the effort coefficient, the service capability coefficient, the communication coefficient, and the information sharing degree coefficient of the pension service providers, while it is positively correlated with the effort cost coefficient, the output sharing coefficient, and the risk aversion coefficient of the pension service providers. The variance of number and external environmental variables is negatively correlated. This research has shown that the trust is a means of incentive for pension service providers to share information. This research has a certain practical significance for improving the service efficiency of the pension services supply chain and optimizing the level of pension services.
\end{abstract}

\section{Introduction}

With the development of the social economy, the needs of the elderly group are becoming more and more diversified. The traditional institutional and family-style care for the aged can no longer meet the needs of the large elderly group; therefore, many industries related to the elderly service industry have been promoted, and the pension service industry has been fully activated. In recent years, the thought of service supply chain management has brought a new perspective to the management reform of the pension service industry. Different from the traditional mode, the service integrator is introduced into the service supply chain, and the service integrator outsources some service modules to some professional service providers. The structure of the pension service supply chain model includes the following: the service providers that provide the support service, the service integrator that acts as the core enterprise in the supply chain to integrate and develop the pension service resources, the customer-oriented service integrator that accepts the services provided by the service providers, and the network with other relevant support units, and the existing pension service resources into the core services, and ultimately delivered to the customers. With the help of the Internet and the big data technology, the supply chain of pension services is guided by the diversified and personalized needs of the elderly service demanders, integrating the logistics, capital flow, information flow, and service flow in the process of pension services, connecting all kinds of pension service providers, pension service integrators, and pension service demanders, so as to provide the real-time, efficient and low-cost pension services for the demanders. The supply chain of pension service is a kind of functional network chain structure. Although the pension service has 
developed into a relatively clear chain structure, there are still some problems to be solved in the process of providing services. In the pension service supply chain, the pension service integrator and the pension service providers constitute the principal-agent relationship. In the actual operation process, both sides make independent decisions based on their own interests, resulting in the consequences of the pension service information asymmetry, and it leads to adverse selection and some moral hazard problems and damages the overall performance of the pension service supply chain. Therefore, solving this problem can help improve the service quality and overall operation efficiency of the pension service supply chain, provide more highquality services for the elderly, and improve their satisfaction, which is of great research value. In addition, it has been proved that the supply chain performance can be improved greatly by the supply chain coordination and the establishment of operational contract mechanism among supply chain members. Therefore, how to achieve the supply chain coordination of pension services, optimize the distribution of benefits, and provide the high-quality and efficient pension services is the focus of this paper.

\section{Literature Review}

2.1. Mode of the Pension Service. In recent years, most of the researches on the mode of the pension service are empirical studies. Wei and Zang used the multistage sampling method to conduct a questionnaire survey among 3260 elderly people aged 60 years or over in 44 communities in 16 subdistricts in six districts in Xiamen [1]. Alders, Peter et al. analyzed the differences in the number of people choosing institutional care between 1996-1999 and 2009-2012 to explain why the institutional care has become lower and the community care has become higher [2]. Based on the difference between urban and rural areas, Liangwen Zhang et al. used the multistage sampling method and constructed the Andersen Model to investigate 7192 elderly over 65 years old living at home and analyzed the present situation of the occupancy rate in nursing institutions and its influencing factors [3]. WenBing Mei et al. used the questionnaire survey and the fuzzy analytic hierarchy process to establish a complete evaluation system of the elderly-friendly community public environmental indicators and explore what are the important indicators of the aging-friendliness of a community public environment [4]. Fetherstonhaugh et al. investigated some home care workers in Australia from November 2018 to January 2019, using a qualitative descriptive design and the semistructured face-to-face and telephone interviews, analyzed the problems in the provision of home care to the older persons, and proposed some corrective measures [5]. Henderson et al. investigated 922 people who worked in nursing homes using both qualitative and quantitative methods to analyze the missing tasks in nursing homes and the causes [6]. Puustinen et al. collected some dates about 71 home care during the spring of 2018, analyzed these data with descriptive statistical method, analyzed the inconsistency between the client needs and the care services, and put forward some relevant solutions [7].
Schonfelder et al. conducted interviews with 16 professional caregivers to investigate how professional caregivers in home care for the elderly in Norway relate their professional tasks to the social care [8]. Suwa et al. investigated and analyzed the views of Japan, Ireland, and Finland on the participation of robots in home care for the elderly by means of questionnaires [9]. Cleland et al. conducted 41 in-depth, semistructured interviews with people over 65 years of age receiving community-based geriatric care in three Australian states to study the quality of community-based geriatric care [10].

2.2. Service Supply Chain. At present, the research on service supply chain mainly focuses on product service supply chain, logistics service supply chain, port service supply chain, medical service supply chain, and cloud service supply chain.

Choudhury et al. reviewed the research methods of service supply chain and suggested that the future research should focus on four main areas of service supply chain, namely, environmental protection measures, market relations, information technology integration, and adoption of industry-specific case studies [11]. Johnson and Mena [12] redefined the supply chain with service flow as product service supply chain, and many scholars also discussed the supply chain management in the context of service [13]. Beuren et al. argued that introducing services into supply chain networks can help many manufacturers find opportunities to change customer consumption patterns and integrated products and services to build process models for product service supply chains [14]. At the same time, a large number of scholars also study the product service supply chain, mainly concentrated in the product before and after sales [15]. Yongtao Peng constructed a product service supply chain network and studied the effects of product and service capacity constraints and product service integration rate on network equilibrium [16].

Han et al. constructed the revenue sharing model of port and shipping service supply chain based on system optimization and studied the revenue sharing decision-making problem of port and shipping service supply chain with government subsidy mechanism [17]. Liu et al. constructed a decision model of dual overconfidence behavior and studied the effects of dual overconfidence behavior and demand renewal on supply chain decision-making by using the method of empirical research [18].

Zhao used the Game Theory to study the coordination of the supply chain of geriatric medical service in a twochannel environment and analyzed the decision-making and interaction between the pension service integrator and the pension service providers in competition and cooperation [19]. De Vrie and Huijsman attempted to integrate the supply chain domain with the health services domain and defined five major research areas of supply chain management in medical institutions [20].

$\mathrm{Lu}$ et al. studied the collaborative supply decision problem of basic service units in cloud service supply chain [21]. Xue and Ge applied the theory of quality cost to the 
research of logistics service supply chain and put forward the method of constructing logistics service supply chain and cost optimization based on cloud genetic algorithm [22].

$\mathrm{He}$ et al. constructed a supply chain of low-carbon services, taking into account corporate social responsibility, consisting of a service providers responsible for carbon reduction and carbon services and a service integrator responsible for low-carbon advertising, and established three differential game models to explore the optimal decisions [23]. Based on the Structural Equation Model, Yingjie Ju discussed the relationship between integrated quality, value cocreation, and the elasticity of logistics service supply chain, analyzed the regulating function of digital technology, and studied the integration of supply chain from a new perspective [24]. Based on the complex network theory, Ma et al. constructed an improved structure model of logistics service supply chain, reconstructed the operation mechanism of logistics service supply chain, determined the vulnerable nodes in logistics service, and clarified the vulnerable mechanism of logistics service center [25]. Based on the structure of logistics service supply chain, Guangsheng Zhang et al. analyzed the evolution of risk and the reactions of major actors [26]. Wang et al. established a nonlinear mixed integer multiobjective optimization model for service providers selection and order assignment in mass customization logistics service mode and designed an improved genetic algorithm based on the multilayer coding technique to solve the model [27]. Li et al. constructed an evolutionary game model to explore the dynamic selection process of enterprise information synergy strategy in logistics service supply chain [28]. Liu et al. studied the impact of loss aversion preference on purchasing decision of service capacity with renewed demand in a logistics service supply chain consisting of a logistics service integrator and functional logistics service providers [29]. Ju et al. established a structural equation model and discussed the factors that affect the performance sustainability of integrators based on their opportunistic behavior [30]. Dai et al. constructed a supply chain logistics service model of blockchain and studied the application of block supply chain technology in logistics service supply chain management from three dimensions: object domain, function domain, and attribute domain [31]. Liu et al. studied the order allocation problem of a logistics service supply chain with one logistics service integrator and two competing functional logistics service providers and proposed an incentive contract [32].

2.3. Incentive Mechanism of Supply Chain. Wang et al. studied a green supply chain consisting of a risk averse downstream retailer and a risk averse upstream supplier and designed the incentive mechanism to improve the product green degree under the compensation contract of the target green degree [33]. Yu et al. proposed a supply chain agent incentive negotiation mechanism to improve the supply chain agent strategy [34]. Lin et al. studied the cooperation mechanism of the supply chain of the four-party (the third party logistics supplier, the bank, the B2B platform operator, and the small and medium-sized enterprises) [35]. Wang et al. proposed a kind of incentive method of knowledge sharing based on supervision mechanism and established the basic incentive model and optimization model of knowledge sharing in industrial building supply chain based on the principal-agent theory [36]. Based on the perspective of sustainable development of supply chain, Jeong et al. studied the effect of quantity incentive contracts on environmental performance, market performance, and profit performance of small and medium enterprises [37].

To sum up, most scholars studied the product supply chain and logistics supply chain, few scholars applied the supply chain theory to the elderly service, and the research results of information sharing incentive in the service supply chain were extremely few. In this paper, the trust degree of the service integrator to the supplier is quantitatively expressed, and the service ability, interaction degree coefficient, information sharing degree coefficient, and so on are considered, and the incentive problem of information sharing between service integrator and service providers in service supply chain is studied. Under the situation that the aging of population is becoming more and more serious, this research has certain theoretical and practical significance.

\section{Problem Description and Basic Assumptions}

Generally, in the pension services supply chain, the service ability and effort level of pension service providers are not easy to be observed by pension service integrator, but their service performance can be observed by the pension service integrator. Therefore, the information asymmetry often occurs in the pension service supply chain, which will bring a series of adverse selection and moral hazard problems, and the existence of these problems will affect the interests of the whole pension service supply chain. This paper attempts to use the principal-agent theory to analyze the principal-agent relationship between the pension service integrator and the providers and constructs an incentive model of information sharing based on mutual trust between them in the pension service supply chain under asymmetric information, so as to encourage the pension service providers to improve the level of pension service and efforts. At the same time, it can achieve the purpose of balancing the interests of each node enterprise and standardizing and restricting the behavior of each node enterprise. This paper makes the following assumptions for the model:

Hypothesis 1. The information about pension service between the pension service integrator and the pension service providers is not asymmetric. A trust incentive coefficient $t$ given by the pension service integrator to the pension service providers is set $(0 \leq t \leq 1)$, and the coefficient is the trust degree of the pension service integrator to the pension service providers. The larger $t$ is, the higher the trust degree of the pension service integrator to the pension service providers is.

Hypothesis 2. The service ability coefficient of the pension service providers is $S_{c}$ (the coefficient is a parameter to measure the service ability of the pension service providers), 
the effort degree coefficient of the pension service providers is $L_{1}$ (the coefficient is a parameter to measure the level of effort pension service providers), and the effort cost coefficient of the pension service providers is $C_{1}$ (the coefficient is a parameter to measure the cost that the pension service providers produces in the process of providing the service), where $S_{C}>0, L_{1} \geq 1\left(L_{1}=1\right.$ means that the pension service providers have not made any effort), and $C_{1}>0$.

Hypothesis 3. The communication degree coefficient between the pension service providers and the pension service integrator is $i$ (the coefficient is a parameter to measure the good communication between the providers and the integrator), the effort degree coefficient paid by the pension service providers is $L_{2}$ (the coefficient is a parameter to measure the degree of effort for the integrator in order to maintain good communication with the integrator) in order to achieve good communication, and the corresponding effort cost coefficient is $C_{2}$ (the coefficient is a parameter to measure the cost of maintaining good communication between the providers and the integrator), where $0 \leq i \leq 1$ ( $i=0$ means that there is no communication between the pension service providers and the pension service integrator at all, $i=1$ means that the communication between the pension service providers and the pension service integrator is perfect, $L_{2} \geq 1$ ( 1 means that the pension service providers have not made any efforts), and $C_{2}>0$.

Hypothesis 4. The information sharing degree coefficient between the pension service providers and the pension service integrator is $S_{d}$ (the coefficient is a parameter to measure the degree of information sharing between the providers and the integrator), the corresponding effort degree coefficient is $L_{3}$, and the effort cost coefficient is $C_{3}$ (the coefficient is a parameter to measure the cost of information sharing between the providers and the integrator), where $0 \leq S_{d} \leq 1$ ( $S_{d}=0$ means that the pension service providers do not share any information with the pension service integrator, $\mathrm{SD}=1$ indicates that the pension service providers can directly and completely share information with the pension service integrator, $L_{3} \geq 1$ ( $L_{3}=1$ indicates that the pension service providers have not made any efforts in information sharing), and $C_{3}>0$.

Hypothesis 5. The external environment variable is $\theta$, and $\theta$ obeys $N\left(0, \delta^{2}\right) ; \theta$ represents the output determined by the uncertainty factors of the external environment, such as changes in market demand and changes in pension service policies.

Assumption 1. The output of pension service provider is $O$ (this variable is a parameter to measure the benefit degree of pension service providers after their efforts), and $O$ meets the following requirements:

$$
O\left(L_{1}, L_{2}, L_{3}\right)=S_{c} L_{1}+i L_{2}+S_{d} L_{3}+\theta .
$$

Assumption 2. The fixed income of the pension service provider is $m$, which has nothing to do with the output; the output sharing coefficient is $n$ (since the income of the pension service provider is partly derived from the resources of the pension service integrator, it is necessary to share part of the income with the pension service integrator), which satisfies $0 \leq n \leq 1$; the linear contract signed between the pension service integrator and the pension service provider is

$$
y(O)=m+(n+t) O
$$

Assumption 3. The effort cost of pension service providers is $C$ (this variable is a parameter to measure the total cost spent by pension service providers):

$$
C\left(L_{1}, L_{2}, L_{3}\right)=\frac{C_{1}}{2} L_{1}^{2}+\frac{C_{2}}{2} L_{2}^{2}+\frac{C_{3}}{2} L_{3}^{2} .
$$

Hypothesis 6. The actual income of the pension service provider is a, and the retained income is $a_{0}$; assuming that the risk of the pension service integrator is neutral, and the risk aversion of the pension service provider, and assuming that the risk aversion coefficient of the pension service provider is $\rho, \rho>0$, then its utility function should beu $(a)=e^{-\rho a}$.

Assumption 4. The pension service integrator's trust in the pension service provider will also generate costs, which are recorded as $C_{t}(t)$. Because when the pension service integrator trusts the efforts and service level of the pension service provider too much, the efforts of the pension service integrator to the pension service provider will produce some more than rational expectations, which may increase the opportunistic behavior of the pension service provider.

$$
C_{t}^{\prime}(t)>0, C_{t}^{\prime \prime}(t)>0, C_{t}(0)=0 .
$$

\section{Trust Incentive Model of Pension Service Supply Chain}

The model of trust motivation in this paper is based on the research model of $\mathrm{He}$ et al. [38]. The original model is described as follows. follows:

The expected revenue of the service integrator is as

$$
E U(o-r(o))=-a+[1-(b+g)]\left(p_{c} f_{5}+i f_{6}+s_{c} f_{7}\right) .
$$

The actual revenue of the service provider is as follows:

$$
\begin{aligned}
m & =r(o)-c\left(f_{5}, f_{6}, f_{7}\right) \\
& =a+(b+g)\left(p_{c} f_{5}+i f_{6}+s_{c} f_{7}+\theta\right)-\frac{d_{5}}{2} f_{5}^{2}-\frac{d_{6}}{2} f_{6}^{2}-\frac{d_{7}}{2} f_{7}^{2} .
\end{aligned}
$$


Determined equivalent benefits of service providers are as follows:

$$
\begin{aligned}
E U(m)-\frac{1}{2} \rho(b+g)^{2} \delta^{2}= & a+(b+g)\left(p_{c} f_{5}+i f_{6}+s_{c} f_{7}\right) \\
& -\frac{d_{5}}{2} f_{5}^{2}-\frac{d_{6}}{2} f_{6}^{2}-\frac{d_{7}}{2} f_{7}^{2}-\frac{1}{2} \rho(b+g)^{2} \delta^{2}
\end{aligned}
$$

This model has been used many times in supply chain construction in other fields and has achieved good results. In this paper, the model is applied to the construction of the pension service supply chain, which also has a certain theoretical and practical significance. Compared with the existing models, the innovation of this paper lies in the addition of a new variable; that is, $C_{t}(t)$ represents the trust cost. On the basis of the above assumptions, this paper proposes the trust incentive model of the pension service supply chain as follows:

The actual revenue of the service provider is as follows:

$$
\begin{aligned}
a= & y(O)-C\left(L_{1}, L_{2}, L_{3}\right)=m+n+t S_{c} L_{1} \\
& +i L_{2}+S_{d} L_{3}+\theta-\frac{C_{1}}{2} L_{1}^{2}-\frac{C_{2}}{2} L_{2}^{2}-\frac{C_{3}}{2} L_{3}^{2} .
\end{aligned}
$$

Determined equivalent benefits of service providers are as follows:

$$
\begin{aligned}
E U(a)-\frac{1}{2} \rho n+t^{2} \delta^{2}= & m+n+t S_{c} L_{1}+i L_{2}+S_{d} L_{3} \\
& -\frac{C_{1}}{2} L_{1}^{2}-\frac{C_{2}}{2} L_{2}^{2}-\frac{C_{3}}{2} L_{3}^{2}-\frac{1}{2} \rho n+t^{2} \delta^{2} .
\end{aligned}
$$

The expected revenue of the service integrator is as follows:

$$
E U(O-y(O))=-m+[1-n+t] S_{c} L_{1}+i L_{2}+S_{d} L_{3}-C_{t}(t) .
$$

Equation (9) calculates the partial derivative of $L_{1}, L_{2}$, and $L_{3}$ respectively, and obtains the incentive compatibility constraint (IC) of the service provider as follows:

$$
\begin{aligned}
& L_{1}=\frac{(n+t) S_{c}}{C_{1}}, \\
& L_{2}=\frac{(n+t) i}{C_{2}}, \\
& L_{3}=\frac{(n+t) S_{d}}{C_{3}} .
\end{aligned}
$$

The trust incentive model of pension service integrator to the pension service providers can be expressed as follows:

$$
\begin{aligned}
& \max \left[-m+[1-n+t] S_{c} L_{1}+i L_{2}+S_{d} L_{3}-C_{t}(t)\right] \\
& \text { s.t } m+n+t S_{c} L_{1}+i L_{2}+S_{d} L_{3}-\frac{C_{1}}{2} L_{1}^{2}-\frac{C_{2}}{2} L_{2}^{2}-\frac{C_{3}}{2} L_{3}^{2}-\frac{1}{2} \rho n+t^{2} \delta^{2} \geq a_{0} \text { (IR) } \\
& L_{1}=\frac{(n+t) S_{c}}{C_{1}}, L_{2}=\frac{(n+t) i}{C_{2}}, L_{3}=\frac{(n+t) S_{d}}{C_{3}}(\mathrm{IC}) .
\end{aligned}
$$

In the above model, IR is the participation constraint of pension service providers, and IC is the incentive compatibility constraint of pension service providers. When the expected return of the pension service provider is less than its retained return, the game between the pension service integrator and the pension service provider will end immediately. In the optimal case, the equation of participation constraint of the pension service provider is established, from which we can get

$$
\begin{aligned}
m= & a_{0}-n+t S_{c} L_{1}+i L_{2}+S_{d} L_{3} \\
& +\frac{C_{1}}{2} L_{1}^{2}+\frac{C_{2}}{2} L_{2}^{2}+\frac{C_{3}}{2} L_{3}^{2}+\frac{1}{2} \rho n+t^{2} \delta^{2} .
\end{aligned}
$$

Combining formulas (11)-(13) and (15), and making the objective function of formula (14) to calculate the partial derivative of $t$, the result can be obtained:

$$
t=\frac{S_{c}^{2} C_{2} C_{3}+i^{2} C_{1} C_{3}+S_{d}^{2} C_{1} C_{2}}{S_{c}^{2} C_{2} C_{3}+i^{2} C_{1} C_{3}+S_{d}^{2} C_{1} C_{2}+\rho \delta^{2} C_{1} C_{2} C_{3}}-n
$$

From equation (11),

$$
t=\frac{C_{1} L_{1}}{S_{c}}-n .
$$

From equation (12),

$$
t=\frac{C_{2} L_{2}}{i}-n
$$

From equation (13),

$$
t=\frac{C_{3} L_{3}}{S_{d}}-n
$$

Formulas (17)-(19) calculate the partial derivatives of $L_{1}, L_{2}$, and $L_{3}$, respectively, and obtain 


$$
\begin{gathered}
\frac{\partial t}{\partial L_{1}}=\frac{C_{1}}{S_{c}}>0, \\
\frac{\partial t}{\partial L_{2}}=\frac{C_{2}}{i}>0, \\
\frac{\partial t}{\partial L_{3}}=\frac{C_{3}}{S_{d}}>0 .
\end{gathered}
$$

Conclusion 1. According to formulas (20)-(22), the trust incentive coefficient given by the pension service integrator is positively related to the effort degree coefficient of the pension service provider. The greater the trust incentive coefficient is, the harder the pension service provider is.

Equation (16) calculates the partial derivatives of $S_{c}, i, S_{d}$, $C_{1}, C_{2}, C_{3}, \delta^{2}, n$, and $\rho$, respectively, and obtains

$$
\begin{aligned}
& \frac{\partial t}{\partial S_{c}}=\frac{2 S_{c} \rho \delta^{2} C_{1} C_{2}^{2} C_{3}^{2}}{S_{c}^{2} C_{2} C_{3}+i^{2} C_{1} C_{3}+S_{d}^{2} C_{1} C_{2}+\rho \delta^{2} C_{1} C_{2} C_{3}{ }^{2}}>0, \\
& \frac{\partial t}{\partial i}=\frac{2 i \rho \delta^{2} C_{1}^{2} C_{2} C_{3}^{2}}{S_{c}^{2} C_{2} C_{3}+i^{2} C_{1} C_{3}+S_{d}^{2} C_{1} C_{2}+\rho \delta^{2} C_{1} C_{2} C_{3}^{2}} \geq 0 \\
& \frac{\partial t}{\partial S_{d}}=\frac{2 S_{d} \rho \delta^{2} C_{1}^{2} C_{2}^{2} C_{3}}{S_{c}^{2} C_{2} C_{3}+i^{2} C_{1} C_{3}+S_{d}^{2} C_{1} C_{2}+\rho \delta^{2} C_{1} C_{2} C_{3}^{2}} \geq 0 \\
& \frac{\partial t}{\partial C_{1}}=-\frac{\rho \delta^{2} C_{1} C_{2} C_{3}\left(i^{2} C_{3}+S_{d}^{2} C_{2}\right)}{S_{c}^{2} C_{2} C_{3}+i^{2} C_{1} C_{3}+S_{d}^{2} C_{1} C_{2}+\rho \delta^{2} C_{1} C_{2} C_{3}^{2}} \leq 0, \\
& \frac{\partial t}{\partial C_{2}}=-\frac{\rho \delta^{2} C_{1} C_{2} C_{3}\left(S_{c}^{2} C_{3}+S_{d}^{2} C_{1}\right)}{S_{c}^{2} C_{2} C_{3}+i^{2} C_{1} C_{3}+S_{d}^{2} C_{1} C_{2}+\rho \delta^{2} C_{1} C_{2} C_{3}^{2}}<0, \\
& \frac{\partial t}{\partial C_{3}}=-\frac{\rho \delta^{2} C_{1} C_{2} C_{3}\left(S_{c}^{2} C_{2}+i^{2} C_{1}\right)}{S_{c}^{2} C_{2} C_{3}+i^{2} C_{1} C_{3}+S_{d}^{2} C_{1} C_{2}+\rho \delta^{2} C_{1} C_{2} C_{3}^{2}}<0, \\
& \frac{\partial t}{\partial \delta^{2}}=-\frac{\rho C_{1} C_{2} C_{3}\left(S_{c}^{2} C_{2} C_{3}+i^{2} C_{1} C_{3}+S_{d}^{2} C_{1} C_{2}\right)}{S_{c}^{2} C_{2} C_{3}+i^{2} C_{1} C_{3}+S_{d}^{2} C_{1} C_{2}+\rho \delta^{2} C_{1} C_{2} C_{3}^{2}}<0, \\
& \frac{\partial t}{\partial n}=-1<0, \\
& \frac{\partial t}{\partial \rho}=-\frac{\delta^{2} C_{1} C_{2} C_{3}\left(S_{c}^{2} C_{2} C_{3}+i^{2} C_{1} C_{3}+S_{d}^{2} C_{1} C_{2}\right)}{S_{c}^{2} C_{2} C_{3}+i^{2} C_{1} C_{3}+S_{d}^{2} C_{1} C_{2}+\rho \delta^{2} C_{1} C_{2} C_{3}^{2}}<0 .
\end{aligned}
$$

Conclusion 2. It can be seen from equations (23)-(25) that the trust incentive coefficient given by the pension service integrator to the pension service provider is positively related to the service ability coefficient, communication degree coefficient, and information sharing degree coefficient of the pension service provider; that is, the more the pension service integrator trusts the pension service provider, the better the service ability of the pension service provider will be, and the pension service provider will also be more willing to actively communicate and interact with pension service integrator, and the pension service providers will be more willing to share information with the pension service integrator.

Conclusion 3. It can be seen from equations (26)-(28) that the trust incentive coefficient given by the pension service integrator to the pension service provider is negatively related to the effort cost coefficient of the pension service provider; that is, the more trust the pension service integrator gives to the pension service provider, the higher the efficiency of the work of the pension service provider is, and the lower the effort cost is. On the contrary, the less trust the pension service integrator gives to the pension service provider, the lower the work efficiency of the pension service provider is, and the greater the effort cost is.

Conclusion 4. It can be seen from equations (29)-(31) that the trust incentive coefficient given by the pension service integrator to the pension service provider is negatively related to the variance, output sharing coefficient, and risk aversion coefficient of the external environment variables of the pension service provider; that is, the more the pension service integrator trusts the pension service provider, the less the uncertainty of the external environment of the pension service provider is, and the easier it is for the pension service integrator to control the pension service provider. The more trust the pension service integrator gives to the pension service provider, the lower the risk aversion coefficient of the pension service provider is. The larger the trust incentive coefficient of pension service integrator to pension service providers, the smaller the output sharing coefficient of pension service providers.

\section{Numerical Simulation of Trust Incentive in the Pension Service Supply Chain}

(i) Through numerical simulation, it is verified that the effort level of pension service providers is positively related to the trust incentive coefficient of pension service providers. Assuming $C_{1}=20$, $S_{c}=280$, and $n=0.2$, substitute the values of $C_{1}, S_{c}$, and $n$ into equation (17), and use SAS software to draw the graph. The result is shown in Figure 1.

(ii) It can be seen from Figure 1 that the trust incentive coefficient given by the pension service integrator to the pension service providers is positively related to the efforts of the pension service providers, which verifies the correctness of Conclusion 1 . In the same way, through numerical simulation to verify that the trust incentive coefficient $t$ is positively related to the service provider's effort $L_{1}$ and $L_{2}$, it can also verify the correctness of Conclusion 1 .

(iii) Through the numerical simulation, it is verified that the service ability of the pension service providers is positively related to the trust incentive coefficient of the pension service integrator. 


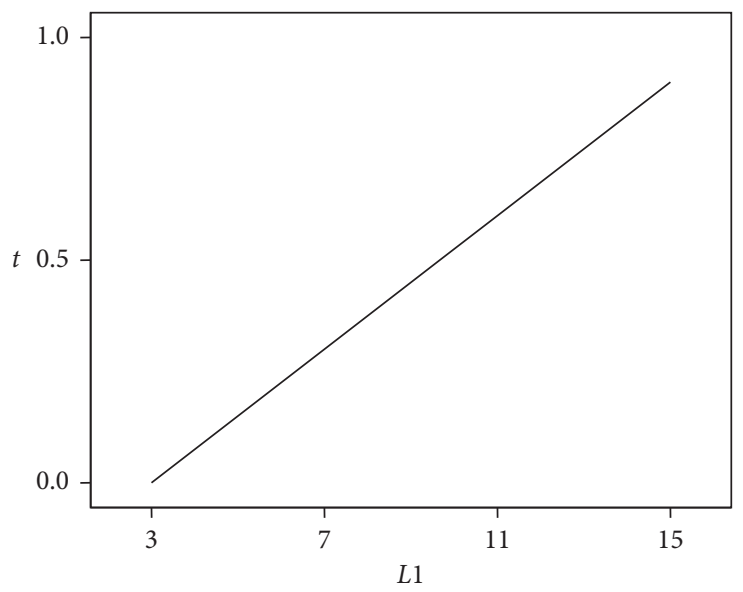

Figure 1: Relationship between effort $L_{1}$ and trust incentive coefficient $t$.

Suppose that $C_{1}=20, C_{2}=0.2, C_{3}=0.4, i=0.5$, $S_{d}=0.6, n=0.2, \rho=0.5$, and $\sigma^{2}=1$, the values of the above parameters are substituted into equation (16), and the SAS software is used for drawing. The results are shown in Figure 2.

(iv) It can be seen from Figure 2 that the trust incentive coefficient given by the pension service integrator to the pension service providers is positively related to the service ability coefficient of the pension service providers, which verifies the correctness of Conclusion 2

(v) Through numerical simulation, it is verified that the communication ability of the pension service providers is positively related to the trust incentive coefficient of the pension service providers. Suppose that $C_{1}=20, C_{2}=0.2, C_{3}=0.4, S_{c}=280$, $S_{d}=0.6, n=0.2, \rho=0.5$, and $\sigma^{2}=1$, the values of the above parameters are substituted into equation (16), and the SAS software is used for drawing. The results are shown in Figure 3.

(vi) It can be seen from Figure 3 that the trust incentive coefficient given by the pension service integrator to the pension service providers is positively related to the communication degree of the pension service providers, which verifies the correctness of Conclusion 2.

(vii) Through numerical simulation, it is verified that the degree of information sharing of pension service providers is positively related to the trust incentive coefficient of pension service providers. Suppose that $C_{1}=20, C_{2}=0.2, C_{3}=0.4, S_{c}=280$, $i=0.5, n=0.2, \rho=0.5$, and $\sigma^{2}=1$, the values of the above parameters are substituted into equation (16), and the SAS software is used for drawing. The results are shown in Figure 4.

(viii) It can be seen from Figure 4 that the trust incentive coefficient given by the pension service integrator to the pension service providers is positively related to the information sharing degree of the pension service providers, which verifies the correctness of Conclusion 2.

(ix) Through numerical simulation to verify that the trust incentive coefficient given by the pension service integrator to the pension service providers is positively related to the effort cost coefficient of the pension service providers, suppose that $S_{c}=280, i=0.5, S_{d}=0.6, C_{2}=0.2, C_{3}=0.4, n=0.2$, $\rho=0.5$, and $\sigma^{2}=1$, the values of the above parameters are substituted into equation (16), and the SAS software is used for drawing. The results are shown in Figure 5.

(x) It can be seen from Figure 5 that the trust incentive coefficient given by the pension service integrator to the pension service providers is negatively related to the service effort cost coefficient of the pension service providers, which verifies the correctness of Conclusion 3. Similarly, through numerical simulation, we can verify $C_{2}=0.2$ and $C_{3}=0.4$, which is also negatively related to the trust incentive coefficient, and also can verify the correctness of Conclusion 3.

(xi) Through numerical simulation, it is verified that the trust incentive coefficient given by the pension service integrator to the pension service providers is negatively related to the risk aversion coefficient of the pension service providers. Suppose that $S_{c}=280, i=0.5, S_{d}=0.6, C_{1}=20, C_{2}=0.2, C_{3}=0.4$, $n=0.2$, and $\sigma^{2}=1$, the values of the above parameters are substituted into equation (16), and the SAS software is used for drawing. The results are shown in Figure 6.

(xii) It can be seen from Figure 6 that the trust incentive coefficient given by the pension service integrator to the pension service providers is negatively related to the risk aversion coefficient of the pension service providers, which verifies the correctness of Conclusion 4. 


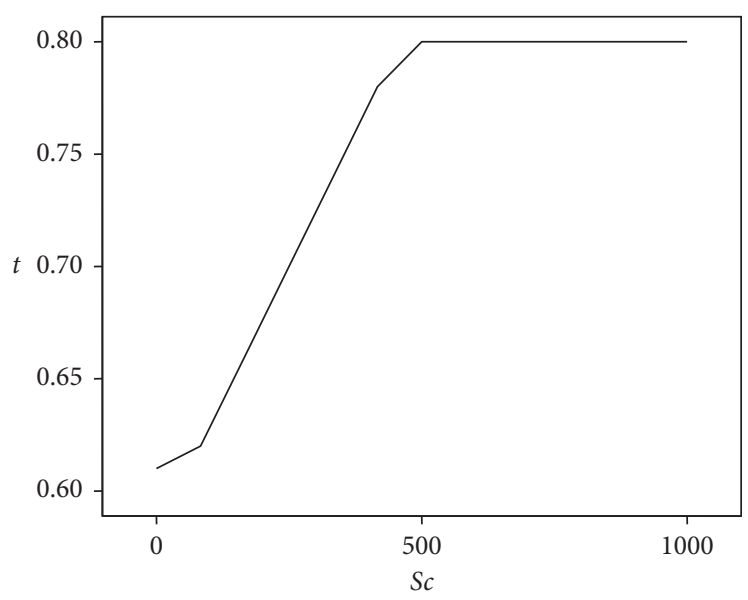

FIGURE 2: Relationship between service ability coefficient SC and trust incentive coefficient $t$ of pension service providers.

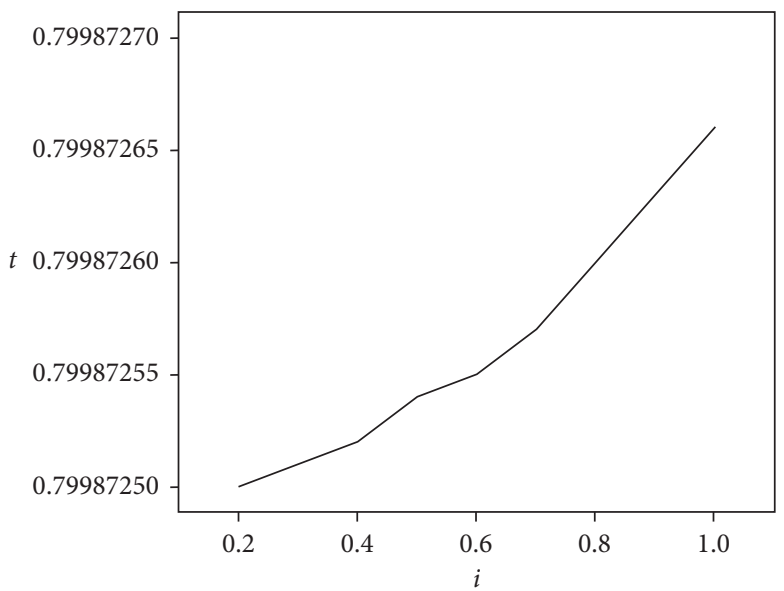

FIGURE 3: Relationship between communication degree coefficient $i$ and trust incentive coefficient $t$ of pension service providers.

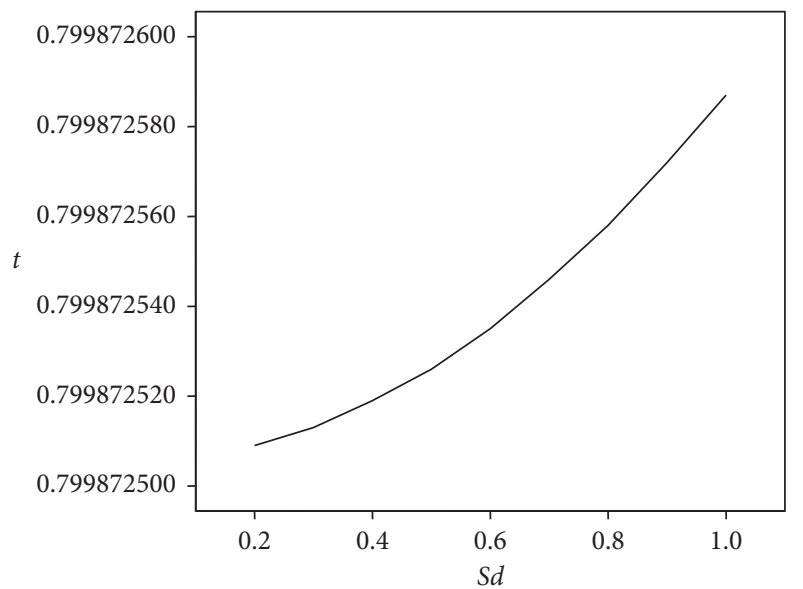

FIGURE 4: Relationship between information sharing degree coefficient $S_{d}$ and trust incentive coefficient $t$ of pension service providers.

(xiii) Through numerical simulation, it is verified that the variance of the external environment variables of the pension service providers is negatively related to the trust incentive coefficient. Suppose that $S_{c}=280, S_{d}=0.6, i=0.5, C_{1}=20, C_{2}=0.2$, $C_{3}=0.4, n=0.2$, and $\rho=0.5$, the values of the above parameters are substituted into equation (16), and the SAS software is used for drawing. The results are shown in Figure 7.

(xiv) It can be seen from Figure 7 that the trust incentive coefficient given by the pension service integrator to the pension service providers is negatively related to the variance of the external environment variables of the pension service providers, which verifies the correctness of Conclusion 4 .

(xv) Through the numerical simulation, it is verified that the trust incentive coefficient given by the pension service integrator to the pension service providers is negatively related to the output sharing coefficient of the pension service providers. Suppose that $S_{c}=280, S_{d}=0.6, i=0.5$, $\rho=0.5$, and $\sigma^{2}=1$, the values of the above parameters are substituted into equation (16), and the SAS software is used for drawing. The results are shown in Figure 8. 


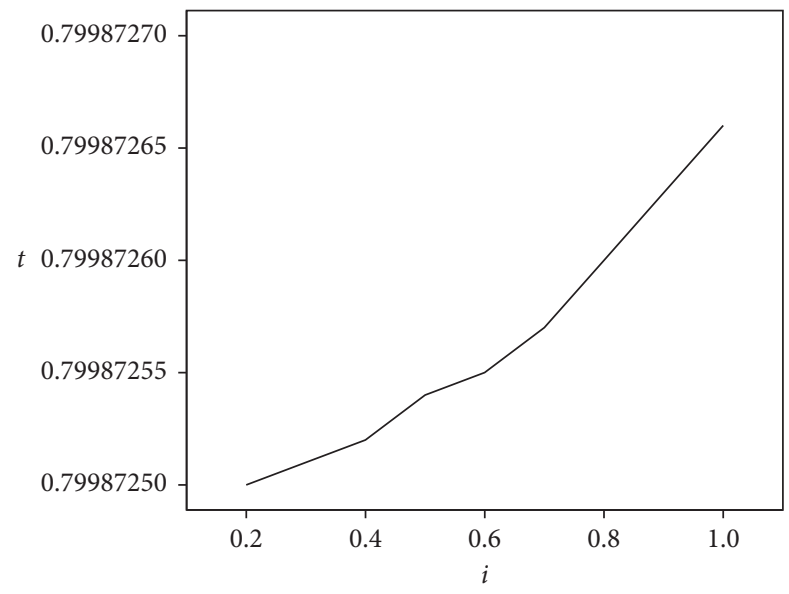

Figure 5: Relationship between effort cost coefficient $C_{1}$ and trust incentive coefficient $t$ of pension service providers.

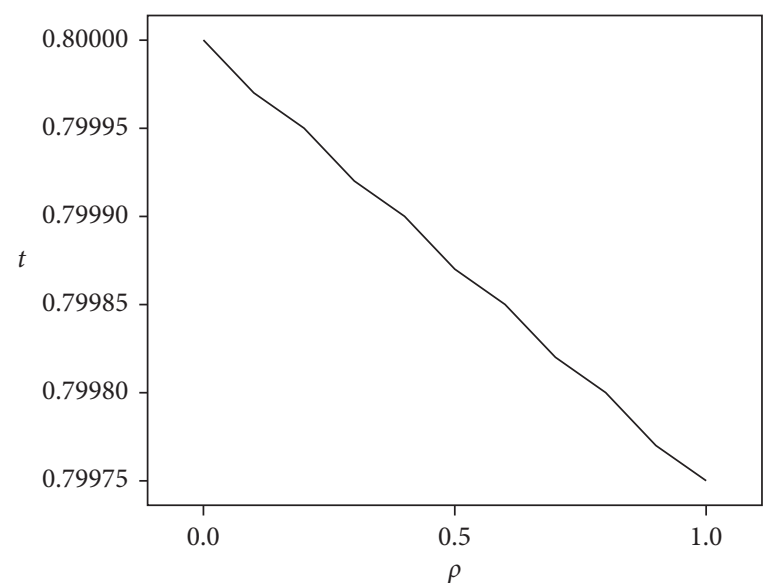

FIGURE 6: Relationship between risk aversion coefficient $\rho$ and trust incentive coefficient $t$ of pension service providers.

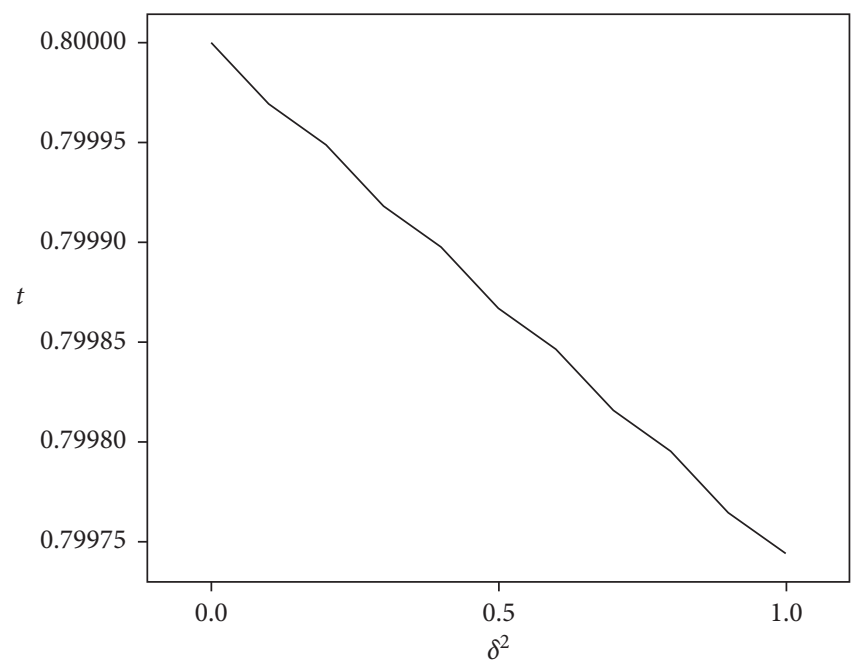

FIGURE 7: Relationship between variance of external environment variables $\delta^{2}$ and trust incentive coefficient $t$. 


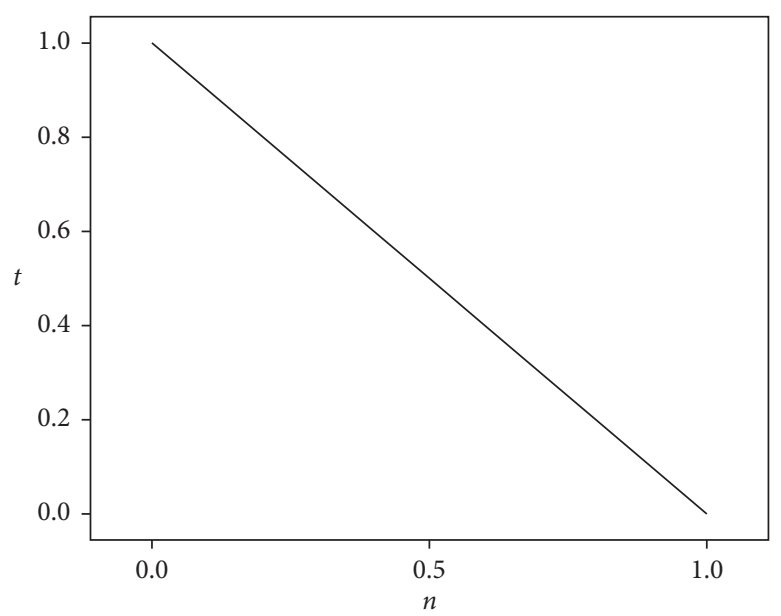

FigURE 8: Relationship between output sharing coefficient $n$ and trust incentive coefficient $t$ of pension service providers.

It can be seen from Figure 8 that the trust incentive coefficient given by the pension service integrator to the pension service providers is negatively related to the output sharing coefficient of the pension service providers, which verifies the correctness of Conclusion 4.

\section{Conclusion}

This paper studies the incentive strategies adopted by the pension service integrator under asymmetric information to encourage the pension service providers to share the pension service information with them and strive to improve the level of pension service. In this paper, the trust coefficient is embedded in the incentive model, the trust incentive model of the pension service supply chain is constructed, and the model is calculated and solved, and the correctness of the conclusion is verified by the numerical simulation. The results show that, under the condition of asymmetric information, the degree of trust incentive given by the pension service integrator to the pension service providers is positively related to the degree of effort, service ability, communication, and information sharing of the pension service providers. The degree of trust incentive given by the pension service integrator to the pension service providers is negatively related to the effort cost, output sharing proportion, risk aversion degree, and variance of external environment variables of the pension service providers.

Based on the above conclusions, several implications are drawn as follows:

(i) The pension service integrator should choose the pension service providers with strong service ability and good communication ability to share information and, at the same time, give them enough trust, so that they can give full play to their abilities;

(ii) The pension service integrator should adopt differentiated trust incentive strategies for the pension service providers. For pension service providers willing to share information and risk, pension service, the integrator should give them full trust. For those with high risk aversion coefficient and low information sharing degree, the pension service providers give less trust;

(iii) The pension service integrator should balance the income incentive and the trust incentive, that is, balance between giving pension service providers a certain degree of trust and output sharing share, which can not only give full play to the role of trust incentive, but also effectively control the loss of opportunistic behavior caused by excessive trust;

(iv) The pension service integrator should strengthen the communication and exchange with the pension service providers, establish a smooth and perfect information sharing platform, and enhance the ability of information receiving and sending between the pension service integrator and the pension service providers.

6.1. Research Expectations. In this paper, a trust incentive model of the supply chain for the elderly service is constructed, and the practicability of the model and the correctness of the conclusion are verified by simulation. The establishment of this model is based on a series of assumptions, but the model has not been tested by empirical evidence. Therefore, the next step of this research will be to do empirical studies by collecting relevant data to verify the usefulness of the model.

\section{Data Availability}

All data and models generated or used during the study are included within the article.

\section{Conflicts of Interest}

The author declares that she has no conflicts of interest regarding the publication of this paper.

\section{Acknowledgments}

This work was partially supported by the Heilongjiang Philosophy and Social Sciences Research Program, 
"Research on Supply Side Reform PATH Optimization, Incentive Mechanism and Satisfaction of Pension Service Industry in Heilongjiang Province" (17JLC126) and "Research on Talent-Gathering Mechanism and Realization PATH of Disruptive Innovation in New Industries in Heilongjiang" (19GLH050).

\section{References}

[1] Y. Wei and L. W. Zhang, "Analysis of the influencing factors on the preferences of the elderly for the combination of medical care and pension in long-term care facilities based on the andersen model," International Journal of Environmental Research and Public Health, vol. 17, no. 15, p. 5436, 2020.

[2] P. Alders, D. J. H. Deeg, and F. T. Schut, "Who will become my co-residents? The role of attractiveness of institutional care in the changing demand for long-term care institutions," Archives of Gerontology and Geriatrics, vol. 81, pp. 91-97, 2019.

[3] L. Zhang, Y. Zeng, L. Wang, and Y. Fang, "Urban-rural differences in long-term care service status and needs among home-based elderly people in China," International Journal of Environmental Research and Public Health, vol. 17, no. 5, p. $1701,2020$.

[4] W. B. Mei, C. Y. Hsu, and S. J. Ou, "Research on evaluation indexes and weights of the aging-friendly community public environment under the community home-based pension model," International Journal of Environmental Research and Public Health, vol. 17, no. 8, p. 2863, 2020.

[5] D. Fetherstonhaugh, J. A. Rayner, K. Solly, and L. McAuliffe, "You become their advocate: the experiences of family carers as advocates for older people with dementia living in residential aged care," Journal of Clinical Nursing, vol. 30, no. 5-6, pp. 676-686, 2021.

[6] J. Henderson, E. Willis, L. Xiao, and I. Blackman, "Missed care in residential aged care in Australia: an exploratory study," Collegian, vol. 24, no. 5, pp. 411-416, 2017.

[7] J. Puustinen, M. Kangasniemi, and R. Turjamaa, "Are comprehensive and individually designed care and service plans for older people's home care a vision or a reality in Finland?" Health \& Social Care in the Community, 2020.

[8] W. Schonfelder, H. Eggebo, and M. C. Munkejord, "Social care for older people - a blind spot in the Norwegian care system," Social Work in Health Care, vol. 59, pp. 631-649, 2020.

[9] S. Suwa, M. Tsujimura, N. Kodate et al., "Exploring perceptions toward home-care robots for older people in Finland, Ireland, and Japan: a comparative questionnaire study," Archives of Gerontology and Geriatrics, vol. 91, Article ID 104178, 2020.

[10] J. Cleland, C. Hutchinson, C. McBain, and R. Walkerm, "Developing dimensions for a new preference-based quality of life instrument for older people receiving aged care services in the community," Quality of Life Research, vol. 29, 2020.

[11] T. T. Choudhury, S. K. Paul, H. F. Rahman, Z. Jia, and N. Shukla, "A systematic literature review on the service supply chain: research agenda and future research directions," Production Planning \& Control, vol. 31, no. 16, pp. 1363-1384, 2020.

[12] M. Johnson and C. Mena, "Supply chain management for servitised products: a multi-industry case study," International Journal of Production Economics, vol. 114, no. 1, pp. 27-39, 2008.
[13] A. Nagurney and T. Wolf, "A cournot-nash-bertrand game theory model of a service-oriented Internet with price and quality competition among network transport providers," Computational Management Science, vol. 11, no. 4, pp. 475502, 2014 .

[14] F. H. Beuren, M. G. Gomes Ferreira, and P. A. Cauchick Miguel, "Product-service systems: a literature review on integrated products and services," Journal of Cleaner Production, vol. 47, pp. 222-231, 2013.

[15] N. Saccani, P. Johansson, and M. Perona, "Configuring the after-sales service supply chain: a multiple case study," International Journal of Production Economics, vol. 110, no. 1-2, pp. 52-69, 2007.

[16] Y. Peng, D. Xu, Y. Li, and K. Wang, "Product service supply chain network equilibrium model considering capacity constraints," Mathematical Problems in Eneineering, vol. 2020, Article ID 1295072, 15 pages, 2020.

[17] B. Han, X. Pan, and Y. Zhou, "Government subsidies and revenue sharing decisions for port and shipping service supply chain in emission control areas," Journal of Advanced Transportation, vol. 2020, Article ID 8892781, 2020.

[18] W. Liu, X. Shen, and D. Wang, “The impacts of dual overconfidence behavior and demand updating on the decisions of port service supply chain: a real case study from China," Annals of Operations Research, vol. 291, no. 1-2, pp. 565-604, 2020.

[19] J. Zhao, "Will the community O2O service supply channel benefit the elderly healthcare service supply chain?" Electronic Commerce Research, vol. 27, 2020.

[20] J. De Vries and R. Huijsman, "Supply chain management in health services: an overview," Supply Chain Management, vol. 16, no. 3, 2011.

[21] X. Lu, Y. xie, J. Wang, and S. Yao, "patent labeling and cooperation in a cloud service supply chain," IEEE Access, vol. 8, pp. 74326-74338.

[22] Y. Xue and L. Ge, "Cost optimization control of logistics service supply chain based on cloud genetic algorithm," Wireless Personal Communications, vol. 102, no. 4, pp. 31713186, 2018.

[23] P. He, Y. He, C. V. Shi, H. Xu, and L. Zhou, "Cost-sharing contract design in a low-carbon service supply chain," Computers \& Industrial Engineering, vol. 139, Article ID 106160, 2020.

[24] Y. Ju, H. Hou, and J. Yang, "Integration quality, value cocreation and resilience in logistics service supply chains: moderating role of digital technology," Industrial Management \& Data Systems, vol. 121, no. 2, pp. 364-380, 2021.

[25] F. Ma, H. Xue, K. F. Yuen et al., "Assessing the vulnerability of logistics service supply chain based on complex network," Sustainability, vol. 12, no. 5, p. 1991, 2020.

[26] G. Zhang, X. Wang, Z. Gao, and T. Xiang, "Research on risk diffusion mechanism of logistics service supply chain in urgent scenarios," Mathematical Problems in Engineering, vol. 2020, no. 12, Article ID 5906901, 2020.

[27] G. Wang, X. Hu, X. Li et al., "Multiobjective decisions for provider selection and order allocation considering the position of the CODP in a logistics service supply chain," Computers \& Industrial Engineering, vol. 140, Article ID 106216, 2020.

[28] G. Li, Q. Zhang, Z. Bai, and P. Sabeeh, "Research on logistics service supply chain information sharing mechanism in the belt and road initiative," IEEE Access, vol. 8, pp. 189684189701, 2020. 
[29] W. Liu, M. Wang, D. Zhu, and L. Zhou, "Service capacity procurement of logistics service supply chain with demand updating and loss-averse preference," Applied Mathematical Modelling, vol. 66, pp. 486-507, 2019.

[30] Y. Ju, Y. Wang, Y. Cheng, and J. Jia, "Investigating the impact factors of the logistics service supply chain for sustainable performance: focused on integrators," Sustainability, vol. 11, no. 2, p. 538, 2019.

[31] H. Dai, Y. Cui, and L. Guo, "J Ma,"Construction and application nanlysis of logistics service supply chain based on block chain," Journal of Environmental Protection and Ecology, vol. 20, no. 3, pp. 1554-1564, 2019.

[32] W. Liu, D. Wang, X. Shen, X. Yan, and W. Wei, "The impacts of distributional and peer-induced fairness concerns on the decision-making of order allocation in logistics service supply chain," Transportation Research Part E: Logistics and Transportation Review, vol. 116, pp. 102-122, 2018.

[33] W. Wang, Y. Zhang, W. Zhang, G. Gao, and H. Zhang, "Incentive mechanisms in a green supply chain under demand uncertainty," Journal of Cleaner Production, vol. 279, Article ID 123636, 2020.

[34] F. Yu, C. Zhang, and Y. Yang, "An incentive mechanismbased negotiation model for green supply chain networks," Transactions of the Institute of Measurement and Control," Article First Published Online, 2020.

[35] Q. Lin and Y. Peng, "Incentive mechanism to prevent moral hazard in online supply chain finance," Electronic Commerce Research, vol. 24, 2019.

[36] Q. Wang and Q. Shi, "The incentive mechanism of knowledge sharing in the industrial construction supply chain based on a supervisory mechanism," Engineering," Construction and Architectural Management, vol. 26, no. 6, pp. 989-1003, 2019.

[37] E. B. Jeong, G. W. Park, and S. H. Yoo, "Incentive mechanism for sustainable improvement in a supply chain," Sustainability, vol. 11, no. 13, Article ID 3508, 2019.

[38] H. Zheng, J. Wang, B. Li, and X. Yang, "Trust incentive model of information sharing in service supply chain," Technology Economy and Management Research, vol. 11, pp. 57-61, 2017. 